\title{
MAS-Based Interaction Simulation within Asymmetric Information on Emergency Management of Urban Rainstorm Disaster
}

\author{
Qing Yang, ${ }^{1}$ Jinmei Wang, ${ }^{2}$ Xingxing Liu $\left({ }^{1},{ }^{1}\right.$ and Jiajia Xia ${ }^{2}$ \\ ${ }^{1}$ School of Safety Science and Emergency Management, Wuhan University of Technology, Wuhan 430070, Hubei, China \\ ${ }^{2}$ School of Management, Wuhan University of Technology, Wuhan 430070, Hubei, China \\ Correspondence should be addressed to Xingxing Liu; liuxingxing@whut.edu.cn
}

Received 25 July 2020; Revised 17 September 2020; Accepted 12 October 2020; Published 26 October 2020

Academic Editor: Peter Bian

Copyright (c) 2020 Qing Yang et al. This is an open access article distributed under the Creative Commons Attribution License, which permits unrestricted use, distribution, and reproduction in any medium, provided the original work is properly cited.

The frequent occurrence of urban waterlogging constantly affects resident living and urban construction. Improved adaptive prevention and control strategies are highly requested due to huge economic losses and casualties caused by flood and waterlogging in China. The urban waterlogging may evolve into a serious emergency, generally characterized by high complexity, uncertainty, and time pressure. Coupled with the asymmetric information, waterlogging often exacerbates the impact of urban rainstorm disasters. Through the multi-agent system simulation with given geographic information, government and residents interact under dynamic risk distribution in rainstorm disaster. The results show that the proactive attitude of residents and the government towards disaster relief could have a promoting effect for both, thereby increasing the disaster relief efficiency. Obviously, rapid accurate information collection and analysis facilitate disaster relief to a large extent. Meanwhile, appropriate supply rather than excessive supply may mobilize residents' self-help and balance replenishment of relief supplies.

\section{Introduction}

Increasingly frequent and severe rainstorms have caused enormous damage and casualties all around the world [1]. Disasters are large intractable problems that test the ability of nations to protect their populations and infrastructure effectively and recover quickly [2]. In addition, teamwork of residents helps much on disaster relief $[3,4]$. Urban rainstorm usually causes serious waterlogging due to heavy precipitation [5-7], which is one of the most common natural disaster phenomena in many big cities in China. Rainstorm waterlogging induced by torrential rain or typhoon has become one of the most frequent and serious natural hazards in many big cities around the world, especially in the coastal cities of the developing countries that are the centres of human inhabit and social-economic development [8].

Waterlogging is a kind of seeper phenomenon due to heavy precipitation or continuous precipitation beyond the urban drainage capacity, which can usually be attributed to rainstorms [5-7]. There are many other causes of urban waterlogging, frequent extreme weather events, change in underlying surface condition, artificial occupancy of the river section, reduction in water storage capacity, urban heat and rain island effect, drainage engineering construction lag, low terrain, and lag-management $[9,10]$. With global warming, the emergence of heavy rainfall is becoming more frequent. Accompanied with the accelerating urbanization, many big cities (such as Beijing, Wuhan, Guangzhou, Nanjing, Hangzhou, Chengdu, and so forth) in China have suffered severe urban waterlogging due to heavy rainfall. Waterlogging occurred in the frequency and scale has expanded for each year, which exposed the vulnerability of major cities in defence of meteorological disasters. Rainstorm disaster often brings much adverse impact on health, traffic, communication, and people's property [11-14].

On June 23, 2011, a rainstorm hit Beijing and caused serious waterlogging and traffic congestion. Many people 
were stuck in the streets and could not get home until late at night. On July 21, 2012, a more powerful rainstorm struck Beijing. Serious waterlogging occurred in some low-lying road sections, and some people even drowned in their cars [15]. During the disaster, 79 people lost their lives, about 1.9 million people suffered, and the total economic damages were almost 10 billion RMB [16]. Thus, a series of problems caused by urban storm waterlogging has become the research focus and more attention is paid to it [17].

Disaster management has everlasting attention [18]. In order to reduce the damage caused by rainstorm disasters, ensure traffic safety, and control emergency cost, extensive rainstorm disaster models have been developed to assess disaster risk and predict the impact of rainstorm disasters as well [19-21]. Wang et al. [22] used the hidden Markov model (HMM) method to conduct a dynamic risk assessment of natural disasters in Dalian, China. Javier Salmerón et al. [23] developed a two-stage stochastic optimization model to guide the relief assets allocation. Mahootchi and Golmohammadi [24] extended the mathematical two-stage stochastic optimization model to provide appropriate response and better service. Sawada and Takasaki [25] established a microeconomic analysis framework between disasters and poverty, revealing that mutual aid is critical to effective poverty alleviation. "Life first" is often seen as the principal rule in the disaster rescue, so as in the rainstorm relief. While hydrological analysis and facility planning occupied major research position in urban rainstorm evolution, like SWMM (Storm Water Management Model) [17], MOUSE (Model for Urban Sewers) [26], etc., various mutual influencing factors underlie the complex system of urban drainage [27]. Actually, owing to the increase of complexity of urban development, the effectiveness and efficiency of modelling is subject to the dynamic parameter optimization [28].

There are many tools for simulating [29] human and social behaviours in emergencies. The use of these tools can help determine the locations of temporary shelter [30] and predict disaster losses [31], which can improve the efficiency of disaster response. Search and rescue are the major parts of disaster response [32], in which agent-based simulation has been proved as a useful method [33]. Tang Jet al. [34] optimized search and rescue using auction-based task allocation scheme through agent-based simulation. Choi et al. [35] developed a flexible and interoperable distributed simulation environment for comprehensive disaster response management. Alsubaie et al. [36] constructed a disaster response plan based on supervisory control and data acquisition (SCADA) systems. Modelling by multi-agent system (MAS) has been a common tendency for the operation of socialeconomic system under changing natural conditions [37], like evacuation route choice of pedestrians in an urban rainstorm [38, 39].

Effective communication and coordination are crucial aspects of emergency management [40]. However, information asymmetry often manifests when one party has more or better information than the other. Agents with more information will have higher expected payoff than those with less [41]. Besides, agents' decisions will have potential distortion due to information asymmetry [42]. The difference of decision among agents therefore has a positive correlation with information asymmetry [43].

\section{Research Method}

2.1. MAS Modelling. Agent-based simulation seems to be a kind of dynamic networks of interacting agents [44]. By specifying the rules between individuals, computer simulations can be used to demonstrate complex behaviour patterns from other simple models [45]. Agent-based simulation is a relatively new approach to modelling systems composed of autonomous, interacting agents [46]. Each individual is able to make decisions based on circumstances and rules [47]. Repetitive interactions are hard to implement with mathematical methods, which in contrast is a peculiarity of agent-based simulation. Agent-based simulation is widely used in many fields to deal with problems covered in complex systems [48], like resource allocation [49], crowd evacuation [50], decision-making systems [51], and cooperative game [52]. The application of agent-based simulation in disaster management can improve search and rescue efficiency [53].

Since the 1990s, agent-modelling platforms such as STARLOGO, SWARM, NETLOGO, REPAST (Recursive Porous Agent Simulation Toolkit), etc. have been developed. REPAST has outstanding scalability for its JAVA programming [54] and has already been used in modelling social behaviour $[55,56]$ and city management with geospatial design [57]. REPAST can be redesigned for diverse practical needs. Bridging the gap between agent-based simulation and actuality is a challenge for MAS modelling, which is often conducted by parallel execution and adaptive control between artificial and real world [58], through the artificial societies-computational experiments-parallel execution (ACP) platform [59] to interact with the real social system and provide reliable support for the management and decision-making of real social scenes. Therefore, the evolution of the situation, co-evolution, and closed-loop feedback are realized.

For deepening our previous study on human reaction in disaster, we followed the previous MAS modelling on rainstorm relief $[38,39]$. Yang et al. analysed the efficiency of disaster relief by considering the crowd psychology of residents and diverse density distribution of relief settlement. However, the study focuses on the outcome generated from diverse pedestrian categories and distribution of shelters, which does not involve the mutual reaction from diverse subjects.

Actually, information asymmetry is inevitable in rainstorm; the interaction between the government and residents underlies the disaster relief efficiency. Exploring the impact on the disaster relief from different initiatives and interactions helps implement disaster situation analysis and disaster relief decision-making reasonably.

2.2. Agent Attributes. The agent is a physical or abstract entity and the basic unit in multi-agent systems (MAS) [60]. From a practical modelling standpoint, the agent is required 
to possess specific characteristics. Here are three basic agents: resident, government, and waterlogging. The settings of these agents attributes are as follows.

2.2.1. Residents. It is assumed that every resident agent has the attributes of direction, energy, information, decision, and reaction from government. Energy represents the basic physiological requirements for residents to survive. When residents perform series of activities, such as walking, wading, etc., energy will be reduced. Meanwhile, residents can also increase their energy, such as government rescue and materials which will increase directly the energy of the residents saved, and the information obtained by the residents will also be converted into energy. Residents must maintain energy greater than zero during the disaster avoidance process, which is boundary for living status. The probability of residents' autonomous disaster avoidance is related to average expected payoff. If disaster avoidance is autonomous, residents may increase the probability of being rescued because they have obtained more disaster information, but they also consume more energy contemporaneously.

2.2.2. Government. In China, disaster relief organizations are a kind of organizations strictly supervised by government, or are simply referred to as government. It is assumed every government agent has attributes of disaster analysis, benefit, and decision. Government arranges the disaster relief actions with limited relief supplies according to the information of rescue from residents. Government dispatches relief resource and rescue team to set up shelters and spread aid response.

(1) Residents and Government Are Rational Men in Disaster Resistance. Every involved participant is a kind of rational man who is self-interested and pursues maximum payoff [61]. When encountering rainstorm risk, residents could make a strategic decision to move out for disaster avoidance autonomously or stay in original place according to individual experience, environmental conditions, and disaster situation [62]. The government could arrange the disaster relief actions or not based on time sequence and relief supplies $[12,63]$. The government has a fixed consumption of disaster relief supplies for single rescued resident.

(2) Residents Have Energy Consumption and Recovery. When rainstorm occurs, the life value [64] of residents will be affected to various extents [2]. Regardless of whether residents behave or not, they have basic consumption of energy to sustain life and self-adjusted recovery factor each cycle time. If residents get rescued, they could get life recovery from relief supplies; then energy could be added to a certain recovery level.

(3) Residents Gain Information. In a rainstorm, residents need to obtain relevant information in time to assist themselves in making decision of disaster avoidance. Information could represent feasible evacuation route, disaster avoidance approach, medical care, food, and so on. Here, information is simplified as the directions to temporary shelter or rescuers. If there does not exist temporary shelter, information is empty. Moreover, residents have a certain probability of capturing information, and the amount of information obtained by the resident is transformed into a type of energy variable for convenience. The information residents own has a diverse value.

(4) Direction and Decision of Residents. Residents use the available information and government's reaction to make the decision strategies to move out for disaster avoidance autonomously or stay in original place and determine the direction on the route to rescue.

(5) Government Analyses the Disaster. The government is the main body of disaster relief to some extent. Not only should they dispatch rescue teams in time and set up disaster relief shelters, but also they must properly analyse the entire rainstorm situation to make more accurate decisions and increase the probability of successful rescue. The more disaster information the government release, the more information asymmetry can be reduced between agents $[65,66]$.

(6) Benefit of Government. Once residents move out for disaster avoidance autonomously, they become disasterresistant subjects, rather than bearers [67, 68]. Residents participating in disaster relief autonomously will help reduce the losses [69], and the government will also gain corresponding benefit from residents' disaster avoidance autonomously [70-72].

The key parameters about the residents and government agents are summarized as Table 1.

2.2.3. Waterlogging. In the rainstorm, there may be many waterlogging places in urban area. The setting of waterlogging is generally obtained in the simulation based on the neighbourhood analysis in spatial analysis. When the surrounding terrain of a certain area is higher than that area and the underground pipe network has insufficient drainage during heavy rain scenarios, waterlogging point will occur. As the rainfall process continues, the waterlogging point will gradually spread. These waterlogging points may lead to risks including traffic congestion, landslides, leakage of electricity, or spread of harmful substance. Residents may lose much energy since waterlogging points may hinder normal order of life; in particular, they have to get across them. To simulate the scenarios which may happen in rainstorm, random test is used to reproduce as many rainstorm disasters as possible.

\subsection{Agent Interaction Rules}

2.3.1. Interaction Rules between Government and Residents. Residents are sensitive to habitats where they live, which underlies evacuation routes. The rescue organization will deploy disaster relief activities and temporary shelters based 
TABle 1: Parameters of resident and government.

\begin{tabular}{lcc}
\hline Agent & Parameter & Symbol \\
\hline \multirow{4}{*}{ Resident } & Life value (energy) & $L$ \\
& Information value & $I$ \\
& Basic consumption & $L$ \\
& Probability of capturing information & $\varepsilon$ \\
& Recovery factor & $\beta$ \\
Government & Rainstorm risk & $\alpha$ \\
& Government benefit & $Q$ \\
& Disaster analysis & $A$ \\
& Disaster analysis coefficient & $\lambda$ \\
& Relief supplies for single resident & $S$ \\
\hline
\end{tabular}

on disaster situation, meteorological data, and geographic information. In general, residents can stay in original place waiting for rescue or search for temporary shelters based on their own circumstances and decision-making modes. Disaster relief organizations arrange the rescue activities and supplies distribution according to distress signals. Affected by factors such as limited relief supplies [73] and rescue time sequence, the disaster relief organizations cannot respond to every affected resident simultaneously in time. How to achieve a greater evacuation rate in short time is extremely critical. Cooperative behaviour between residents and disaster relief organizations within information asymmetry could have a vital impact on disaster relief. In fact, the decisions of both will affect their benefits and loss, which forms an interaction within asymmetric disaster information between government and residents in rainstorm disaster management.

The simulation is terminated when all residents move out for disaster avoidance autonomously or relief supplies are exhausted. Starting points of residents and shelter points are not unique since diverse situations of disaster need to be simulated. A common disaster relief process is shown in Figure 1. When residents arrive at a shelter or their energy is less than zero, their activities are terminated.

2.3.2. Disaster Relief Rules of Government. In the rainstorm disaster, the government will set shelters and dispatch rescue groups according to the calling for help from residents. The government will distribute the relief materials needed by the residents to various rescue groups. Meanwhile, residents can search for the rescue shelters or stay at original place waiting for help according to their own plight and rescue signals from government. Limited by resources for disaster relief and space-time barrier, it cannot be guaranteed that all residents get satisfied rescue. Efficient distributing control and cooperative work really underlie effective disaster resistance. Furthermore, the residents' resistance for disaster can facilitate disaster relief [74].

Generally, rescue teams are dispatched to cover every disaster area as much as possible. When residents encounter a rescue team, they can get relief resources to recharge their energy and information of shelters and risk distribution of disaster simultaneously. Rescue teams can make a fixed place as a shelter to implement allocation of relief for neighbour residents.

In each round of model evolution, there are different rates of government response, combined with the previous agents attributes and interaction rules; the evolution formula is shown in equation (1):

$$
\begin{aligned}
& P_{t+1}^{G}=P_{t}^{G}+\left[\frac{P_{t}^{G} *\left(1-P_{t}^{G}\right)\left(E^{\mathrm{PG}}-\bar{E}^{G}\right)}{\bar{E}^{\mathrm{PG}}}\right], \\
& E^{\mathrm{PG}}=\left(1-P_{t}^{G}\right)\left(P_{t}^{R} \lambda A-\alpha S\right)+\bar{E}^{G} .
\end{aligned}
$$

$P^{G}$ represents the possibility of rescue groups distributed on the map to start rescue. $P^{R}$ represents the possibility of residents moving out for disaster avoidance autonomously. $P_{t}^{G}$ and $P_{t}^{R}$ represent the probability at certain time $t . E^{\mathrm{PG}}$ represents the relief performance of each rescue group in equation (2). $\bar{E}^{\mathrm{PG}}$ represents average performance. $\bar{E}^{G}$ represents the disaster relief effectiveness of government.

The probability of disaster relief in the next stage of the government is determined by the probability of disaster relief in the previous stage and relief performance. On the one hand, the relief performance of each rescue team is determined by the government's disaster relief efficiency, and on the other hand, it is related to the government's overall disaster relief payoff and loss.

2.3.3. Disaster Avoidance Rules of Residents. If residents move out for disaster avoidance autonomously, government can get positive feedback from residents, like reduction of relief demand, timely information collection, and efficient resource allocation. In the simulation process, the disaster relief information researched by government can also help residents avoid disasters.

During the simulation process, the number of participants play a vital role in analysing the law of evolution. In order to depict positive attitude and activeness of all subjects involved in disaster resistance, Entire Reaction (ER) ratio could be a simple and useful index to evaluate the effects of different strategies, where the calculation formula is shown as follows:

$$
\mathrm{ER}=\frac{N-n}{N}
$$

$N$ denotes the total of residents. $n$ refers to the number of residents who stay at original place without receiving government assistance. Otherwise, either residents or government takes actions for disaster avoidance autonomously and rescue, respectively. In particular, the residents who move out for disaster avoidance autonomously without receiving government assistance are also attributed to reaction process since the rescue for mobile individual is an intermediate status. Residents in search of getting rescue could bring themselves risk but also opportunity.

In each round of model evolution, there are different rates of residents who make decision of disaster avoidance autonomously, combined with the previous agents' 


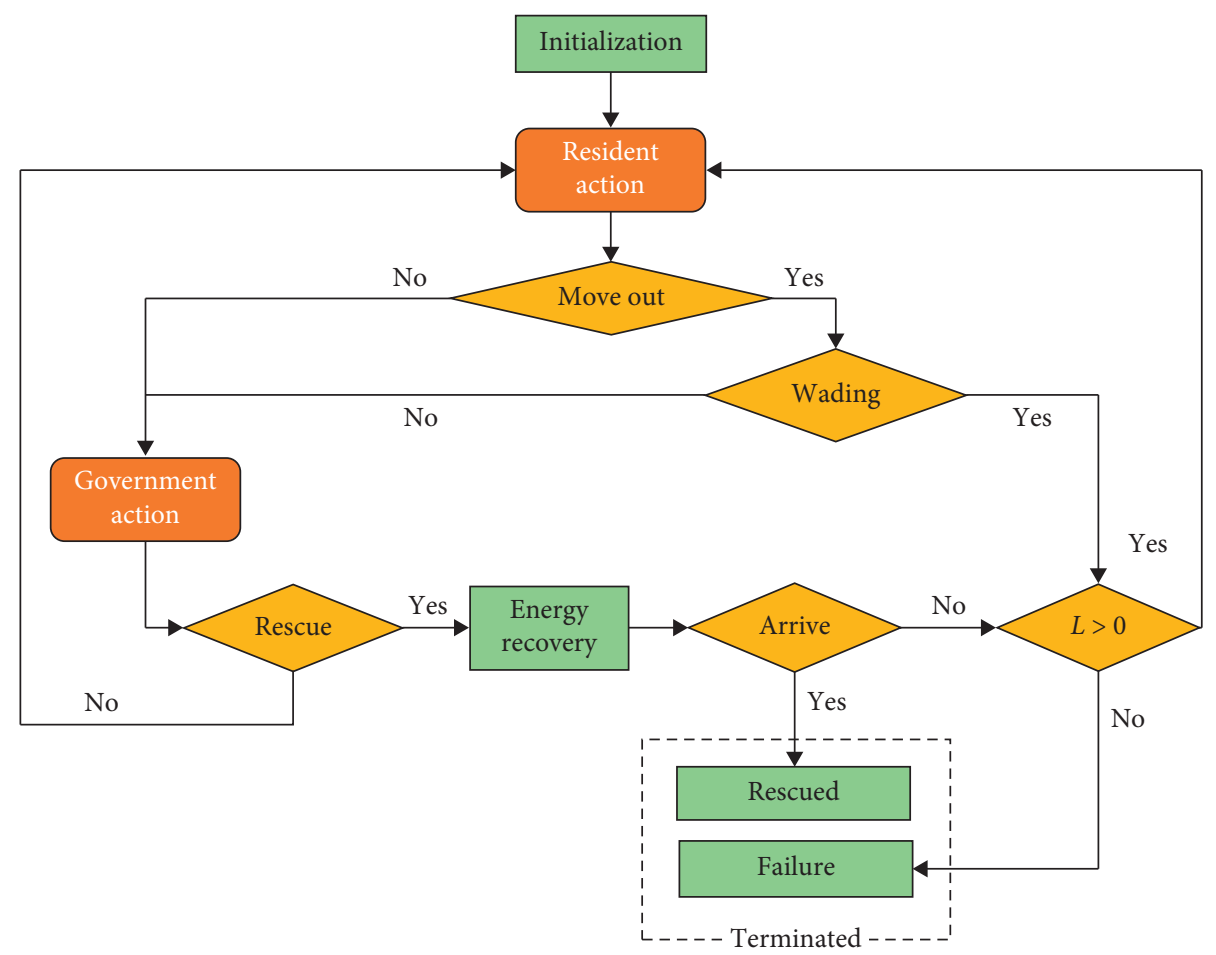

Figure 1: Common disaster relief process.

attributes and interaction rules; the evolution formula is shown in equation (4).

$$
\begin{aligned}
P_{t+1}^{R}= & P_{t}^{R}+\left[\frac{P_{t}^{R} *\left(1-P_{t}^{R}\right)\left(E^{\mathrm{PR}}-\bar{E}^{R}\right)}{\bar{E}^{\mathrm{PR}}}\right] \\
E^{\mathrm{PR}}= & \left(1-P_{t}^{R}\right)\left(\alpha P_{t}^{G}-\alpha \beta P_{t}^{G}-\alpha\right) L \\
& +\left(P_{t}^{G}-P_{t}^{G} \varepsilon+\varepsilon\right) I+\bar{E}^{R} .
\end{aligned}
$$

$E^{\mathrm{PR}}$ represents the performance of each resident who moves out for disaster avoidance autonomously in equation (5). $\bar{E}^{\mathrm{PR}}$ represents average performance. $\bar{E}^{R}$ represents the disaster relief and anti-disaster effectiveness of residents.

The avoiding disaster probability of residents in the next stage is determined by the avoiding disaster probability of the previous stage and avoiding disaster performance. The performance of residents choosing avoid disaster automatically is limited by the residents' avoiding disaster effectiveness on the one hand and related to the residents' energy gains and losses and information acquisition on the other.

2.4. Simulation Area. Considering great similarities among regional plans in Wuhan, a typical community (a certain area) in Wuhan (N $29^{\circ} 58^{\prime} \sim 31^{\circ} 22^{\prime}$ and $E 113^{\circ} 41^{\prime} \sim 115^{\circ} 05^{\prime}$ ), Hubei province in China, is constructed to provide an illustrative disaster relief process. Wuhan has over 10 million people in $8569 \mathrm{~km}^{2}$, the biggest city in the central district of China. Wuhan is also an international city with rapid urbanization. Subtropical monsoon brings much rain to Wuhan especially from June to August. The average annual rainfall in Wuhan was approximately $1200 \mathrm{~mm}$ from 2017 to 2019. The rainstorm in July 2016 had caused 14 deaths and a great direct economic loss of 4 billion RMB.

There are different houses as the starting positions of residents and disaster relief points set by the government. The roads are intricate and complicated to set up different waterlogging points. The simulation map is shown in Figure 2.

The green circles represent residents who walk along the road shown by polylines. When walking, residents may come across a lot of waterlogging points displayed as red forks (shown in Figure 3, one running screenshot of simulation). Residents may spend some energy and time to complete these actions. Residents aim at reducing the loss rate of energy and reaching the shelters.

Considering the density of houses and spatial distance, 4 residents' start points, 3 start points of rescue teams, and 3 shelters are set in different locations. Discrete and random initial settings may evolve into many emerging scenarios. Strict settings from practical situation may restrict the possible evolution processing, which is against ACP. The population of residents is 50 for reducing computing load.

\section{Results and Discussion}

Comparative analysis of possible situations could help understand the origins. Display using geographic information system (GIS) is meaningful for locating disaster of emergency rescue. Through agent-modelling simulation, the evolutions of diverse situation can be discovered and visualized. Table 2 shows the initial value setting of each parameter. 


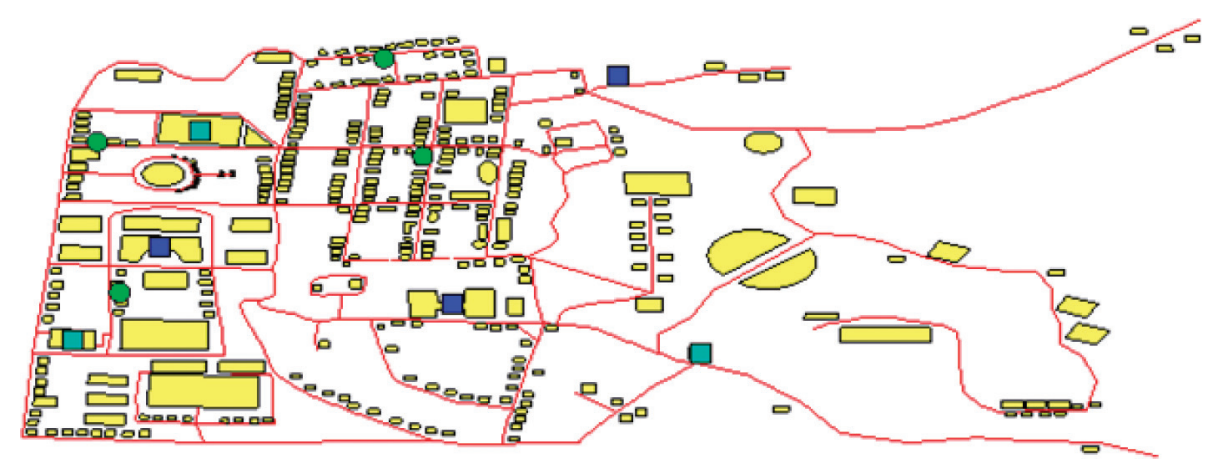

Shelter

Residents

Rescue teams

House

Road

FIGURE 2: Initial display of rainstorm disaster simulation using Repast.

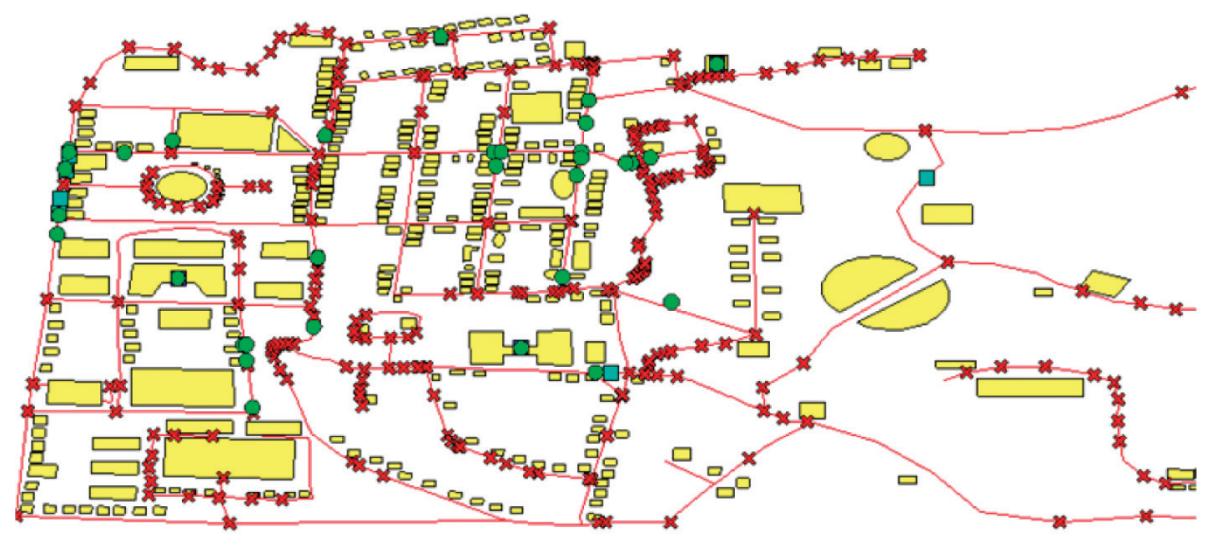

* Waterlogging point

FIgURE 3: Running display of rainstorm disaster simulation using Repast.

TABle 2: Parameter setting list.

\begin{tabular}{lcc}
\hline Parameter & Description & Value (initialization) \\
\hline$L$ & Life value (energy) & 3000 \\
$I$ & Information value & 1500 \\
$L$ & Basic consumption & 1200 \\
$\varepsilon$ & Information delivery & 0.3 \\
$\beta$ & Recovery factor & 0.5 \\
$Q$ & Government benefit & 500 \\
$A$ & Disaster analysis & 800 \\
$\lambda$ & Disaster analysis coefficient & 0.6 \\
$S$ & Relief supplies for a single & 120 \\
\hline
\end{tabular}

The setting of each parameter is based on the general situation, and it will change with the interaction process. Some parameters do not depend on the initial value (such as recovery factor), and some parameters are only used for measurement (such as energy).

From 150 experiments, the average energy consumption of disaster-affected agents is shown in Figure 4. The average energy consumption roughly follows the normal distribution. The mode of average energy consumption is within
1100-1300. In the evolution process, the rainstorm risk coefficient $\alpha$ (the ratio of the energy consumption to the energy) reflecting the main decision interval of a rational person is $[0.37,0.43]$.

3.1. The Best Action of Residents and Government within Asymmetric Information. According to the statistics, the energy consumption conforms to the normal distribution in the evacuation process. The basic life value (energy) of each agent is 1200 , close to the mode of the simulation experiment results. Nearly half of the residents' energy consumption is more than 1200 in the evacuation process, which means it is necessary for the government to carry out rescue like providing energy to the residents.

While there are also many residents who consume less energy in the evacuation process for various reasons, such as being closer to the rescue point, knowing correct evacuation direction, encountering rescue team, and so on, these scenarios do not mean no energy supplement for those residents. 


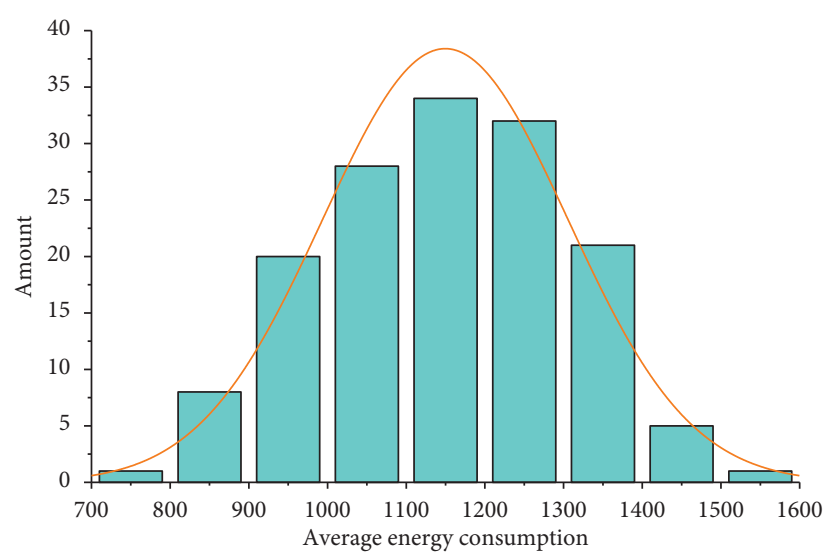

FIgURE 4: Statistics on average energy consumption.

In the process of disaster relief, information asymmetry between the two agents makes it difficult for each other to make effective and helpful decisions. Residents need to decide whether to move out for disaster avoidance autonomously or stay in original place to wait for rescue based on their own disaster information. The government needs to make decisions based on own disaster relief resources and disaster analysis results and then determine the strategy of dispatching rescue teams and the establishment of temporary shelters. The average remaining energy of residents is used to depict efficiency of disaster relief of different probabilities.

Figure 5 shows the average remaining energy of residents of different rescue probabilities of the government. Obviously, when $P^{G}=0.7$, a maximum value is obtained; then it starts to decrease. So, it is inferred that when the government's disaster relief probability is around 0.7 , greater disaster relief efficiency will be achieved.

Figure 6 that has two maxima shows the final average remaining energy of different disaster avoidance probabilities of residents. The first maximum occurs at $P^{R}=0.22$; although the residents can obtain the maximum residual energy, the probability of the residents staying in original place is very high, which may increase the difficulty of the government's disaster relief process. The second maximum is obtained at $P^{R}=0.54$. Although the remaining energy is smaller than the counterpart at $P^{R}=0.22$, it is still greater than the initial energy of 3000. It convinces us about the fact that when the residents' disaster avoidance probability is around 0.54 , the maximum disaster relief efficiency can be obtained for both agents.

3.2. Entire Reaction Analysis. In the simulation process, the choices of residents and government influence each other. Entire Reaction (ER) describes the positive attitude and enthusiasm of all agents involved in disaster relief, analysing the ER of different strategies to reflect the overall disaster relief efficiency. Figure 7 reveals the positivity evolution of disaster relief and avoidance of government and residents and evolution with Entire Reaction.
Figure 7 (a) shows $P^{G}$ tends to approach $100 \%$ and $P^{R}$ tends to approach 0.8 when starting from $P^{G}=P^{R}=0.3$. Government's strategy becomes stable on 1 at half of the simulation. ER climbs to high level at an early stage shown in Figure 7(b).

As can be observed in Figure 7(a), with the increase of the government's disaster relief probability, the residents' disaster avoidance probability decreases firstly and then increases, indicating that the government's low response speed has not stimulated residents' automatic disaster avoidance. When the government's disaster relief efficiency reaches 0.7 , the residents' disaster avoidance probability is stable at 0.8 , which is consistent with the previous analysis of the government's best disaster relief efficiency of 0.7.

The steady increase of ER from Figure 7(b) means that, with the interaction of both agents, residents and government will make decisions to avoid disasters and relief disaster, respectively, which will increase disaster relief efficiency.

Figure 8 reveals the proportion that residents move out for disaster avoidance autonomously with $P^{G}=0.5$. The value of $P^{R}$ fluctuates around the initial value $P^{R}=0.5$. The corresponding ER waves between 0.6 and 0.8 .

When the government's disaster relief efficiency is fixed at a low level, the residents' disaster avoidance probability will also be very low, and the ER will also be at a very low level, which shows that when one side's disaster relief attitude is negative, it cannot stimulate the other side's efficient avoiding disaster autonomously.

For instance, in a rainstorm disaster, the government and residents must rely on themselves independently because of asymmetric information. When residents move out for disaster avoidance autonomously, the government might accept them during the disaster relief process, which will increase the efficiency of the government's disaster relief and convey positive feedback to increase residents' confidence in disaster resistance.

3.3. The Impact of Government Disaster Analysis. Information is a very important recourse in the process of disaster relief and emergency management. The amount of 


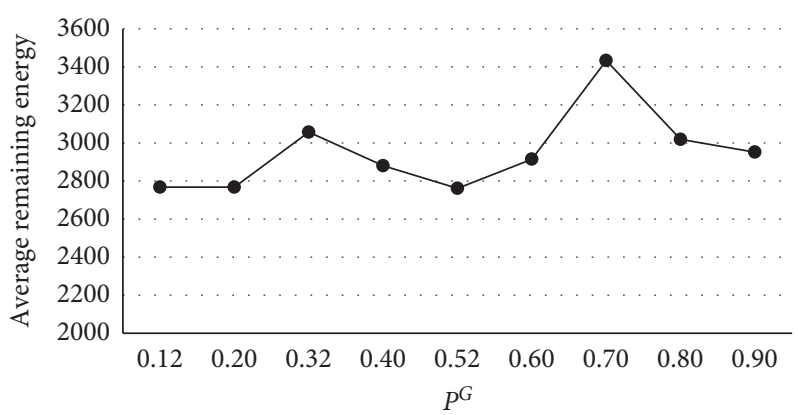

FIgURE 5: Average remaining energy with different relief probabilities of government.

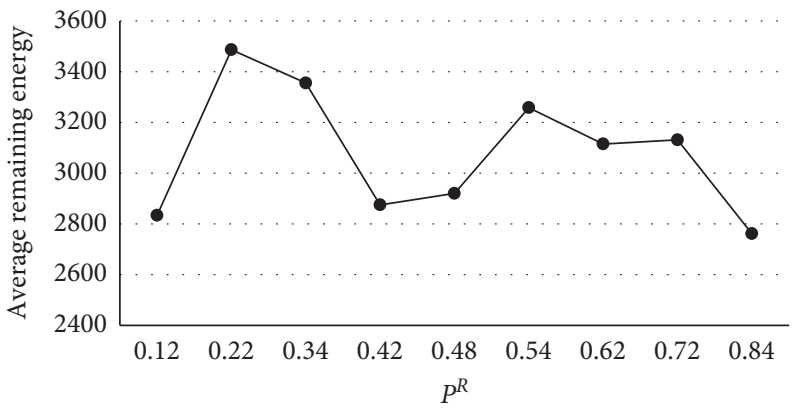

FIGURE 6: Average remaining energy of different disaster avoidance probabilities of residents.

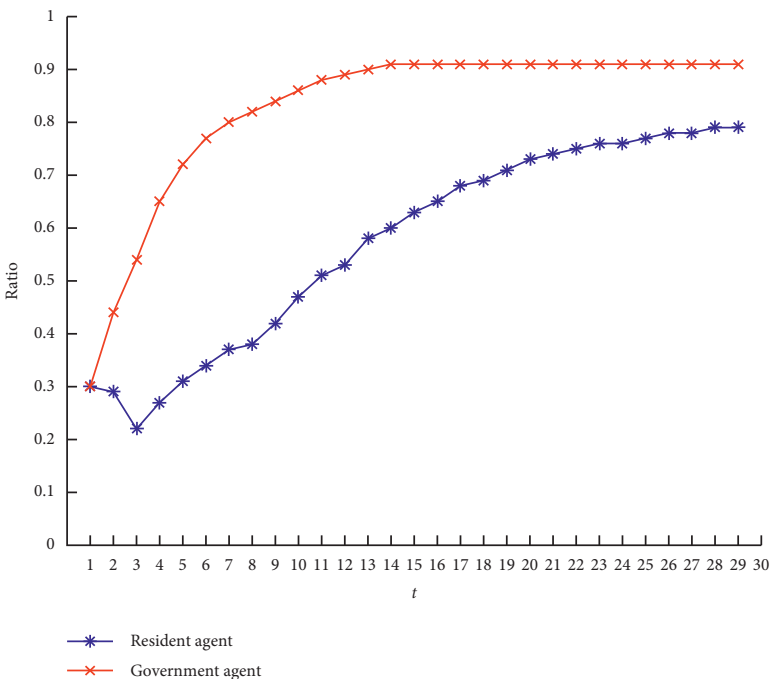

(a)

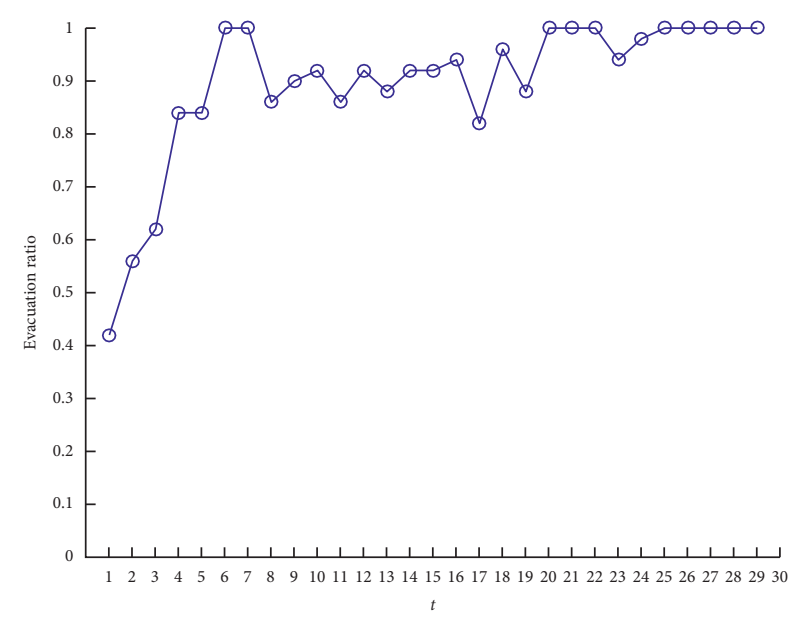

(b)

Figure 7: Evolution with initial $P^{R}=0.3$ and $P^{G}=0.3$. (a) Evolution of $P^{G}$ and $P^{R}$. (b) Entire Reaction.

information directly affects the decisions of both agents, so all involved agents must collect as much information as possible to help them make the most appropriate decision. Residents are often weak agents in the process of avoiding disaster and collect existing information without much capability to research useful information individually. Generally, government can do information concentration and dissemination with complex disaster analysis which could guide disaster relief activities. Figure 9 reveals the positivity evolution of disaster relief and avoidance of government and residents without disaster analysis and with disaster analysis.

Figure 9(a) depicts the strategies evolution when government arranges rescue regardless of analysing disaster. Government and residents both are apt to decline the active strategies. On the contrary, Figure 9(b) shows that if 


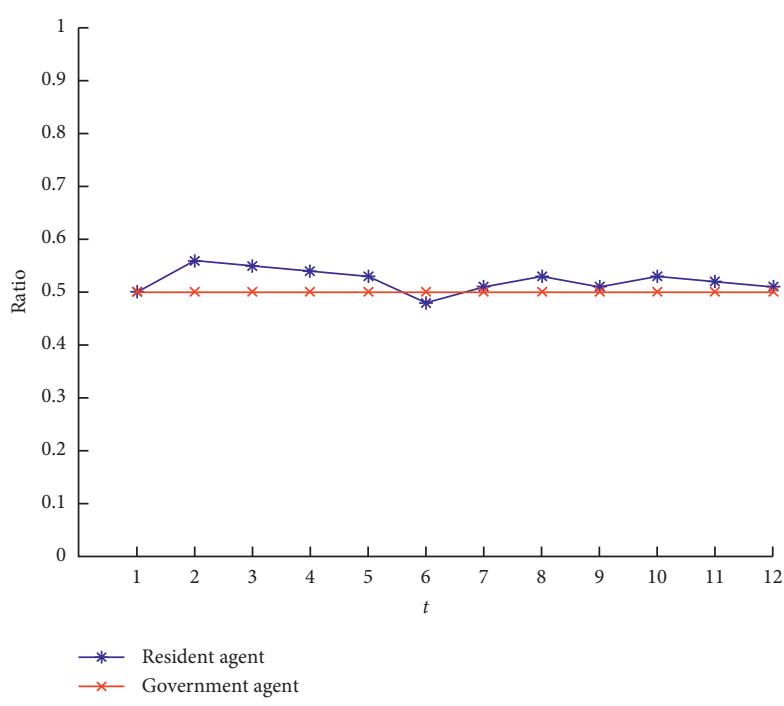

(a)

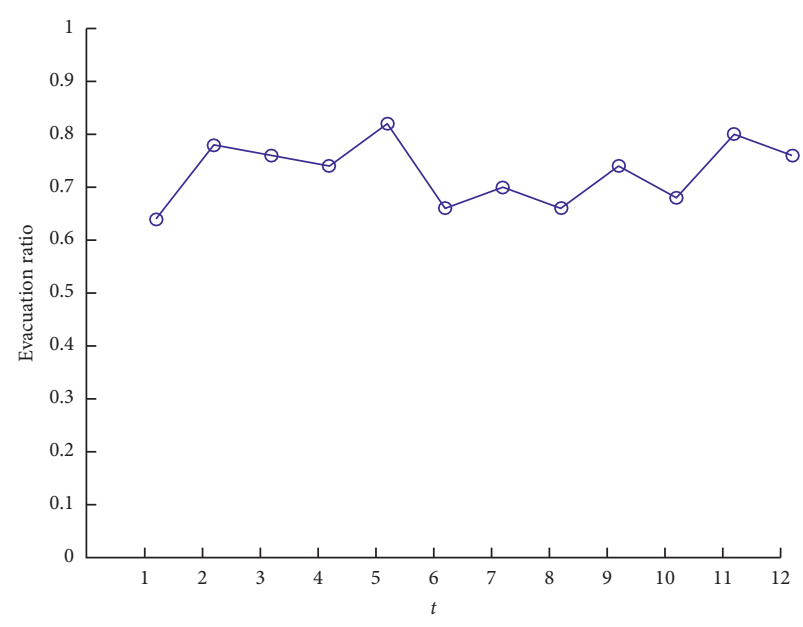

(b)

Figure 8: Evolution with fixed $P^{G}=0.5$. (a) Evolution of $P^{G}$ and $P^{R}$. (b) Entire Reaction.

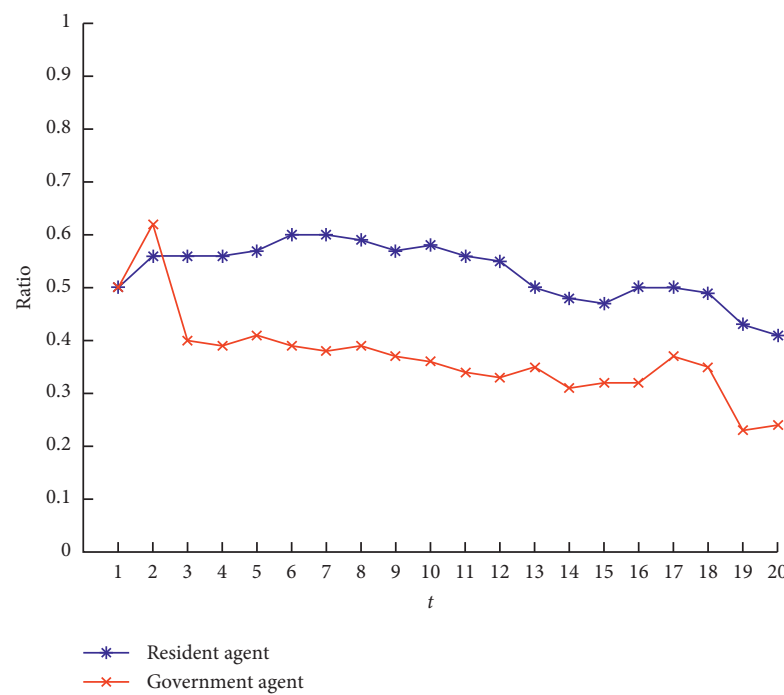

(a)

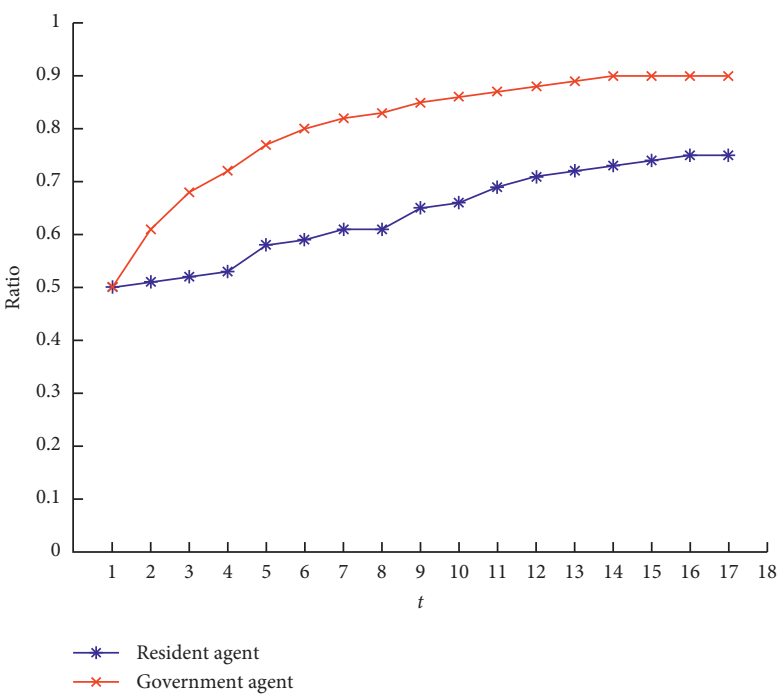

(b)

FIGURE 9: Evolution with binary choice of analysing disaster. (a) Regardless of analysing disaster. (b) Disaster analysis matters.

government cares about analysing disaster in the process of disaster relief, both government and residents tend to perform actively.

3.4. Relief Supplies for Single Resident Analysis. Because of high uncertainty and time urgency, governments usually stockpile a certain amount of relief supplies in advance of potential disasters. Hence, governments face inventory risk and stock-out risk in the relief supply management. The stored relief supplies by governments are wasted if no disaster happens. If the quantity of stored relief supplies is not sufficient, stock-out risk will occur [75]. It is of significance for government to determine the relief supplies for a single rescued resident. By analysing the relief supplies of a single resident when they are rescued, it is possible to explore the actions of both agents and help the government make better decisions. To explore government's and residents' positivity of disaster relief and avoidance about different amount of relief supplies in urban rainstorms, the variations in relief supplies in low level (Figure 10(a)), medium level (Figure 10(b)), and high level (Figure 10(c)) amounts are studied through simulation. Figure 10 reveals the positivity evolution of disaster relief and avoidance of government and residents with different levels of relief supplies.

Comparing Figure 10(a) with Figure 10(b), the reactions of government and residents do not change a lot when $S$ rises from 120 to 240 . It cannot be neglected that there is a slight 


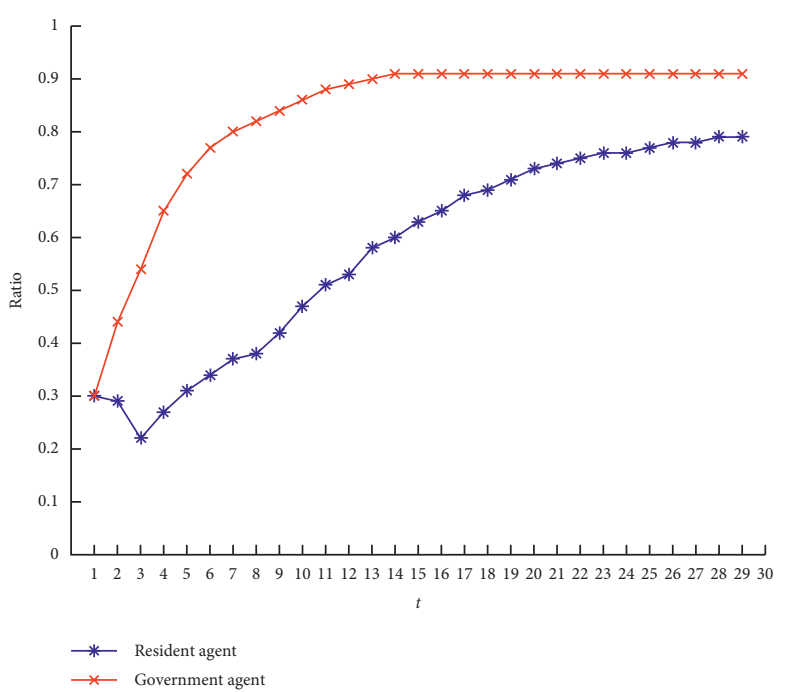

(a)

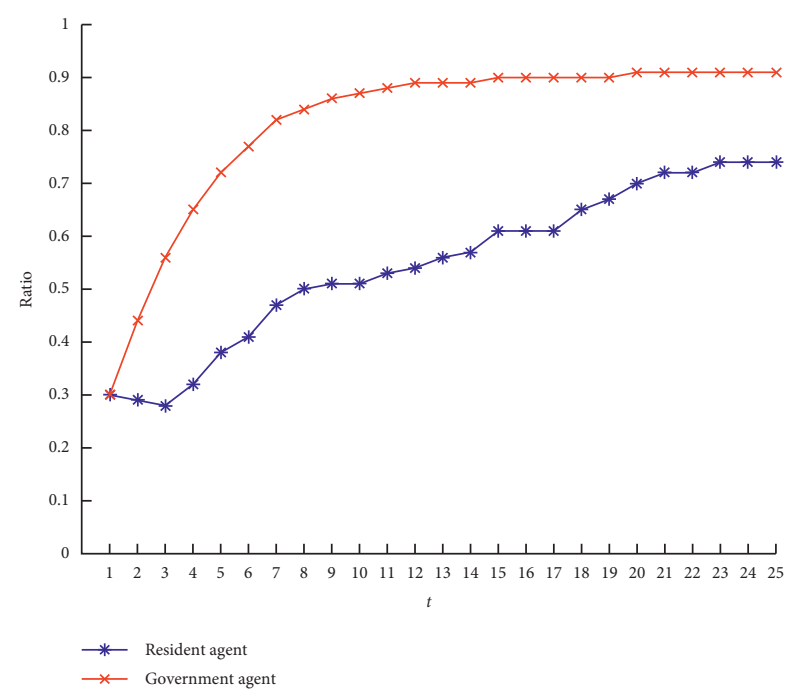

(b)

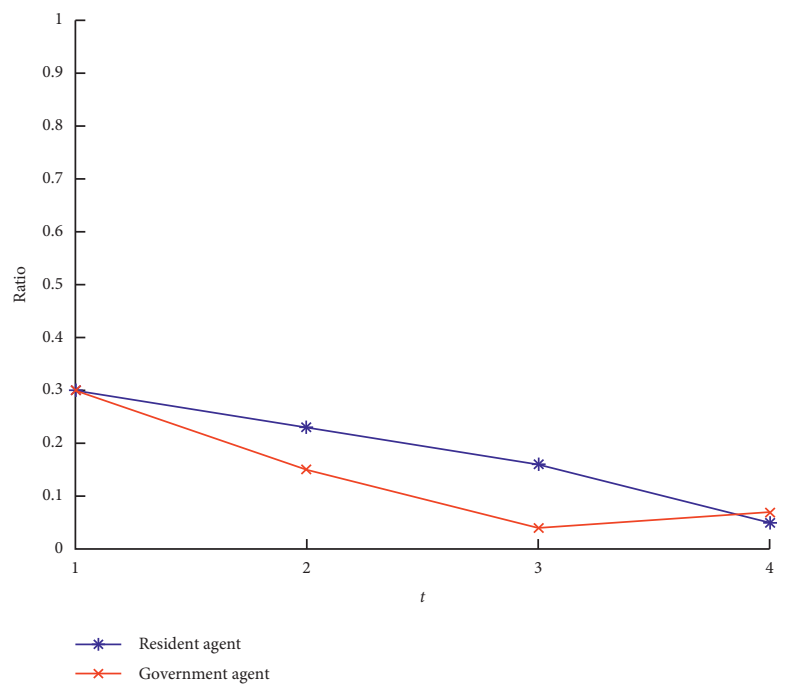

(c)

Figure 10: The evolution with the different $S$. (a) Evolution with $S=120$. (b) Evolution with $S=240$. (c) Evolution with $S=480$.

decrease when $S$ increases. However, residents and government would reduce reactions if $S$ is adequate like the simulated $S=480$ shown in Figure 10(c), which denotes that sufficient relief supplies may make all involved agents more tolerant of disaster.

Specifically, the greater the $S$, the greater the pressure on the government to undertake disaster relief, and the more energy supplements residents receive when rescued, which will lead to both agents being inactive in disaster relief. To conclude, it is difficult for the government to bear huge relief supplies for a single resident, and residents expect to wait in original place for getting enough supplies.

\section{Conclusions}

The rainstorm disaster has caused great losses and harm to human beings. June-September each year is the flood season in China; nearly one-third of the cities are directly affected by the rainstorms and floods. The cities need to be resiliently transformed. Flood prevention and drainage have become an important part of urban modernization. China has also given a lot of investment to improve urban waterlogging problems and maintain people's normal living order. However, in the context of "small government, big society," the overall security of the country requires the participation of all members of the society.

Exploring residents evacuation discipline and effective rescue is an important part of it. The asymmetry information between the government and residents is the most difficult factor. In this paper, the MAS method is used to simulate the government's and residents' strategic choices after the rainstorm disaster in the city. The main conclusions are as follows:

(1) In the process of disaster relief, it is of great significance to determine the best decision strategy of residents and government. Considering the research background, it can be concluded that the best 
probability for residents to avoid disaster automatically is 0.54 , and the best probability for the government to relief disaster is 0.7 .

(2) The interaction between residents and the government can improve the efficiency of disaster relief. Maintaining a positive attitude towards disaster relief between government and residents will stimulate both agents to act actively and enhance Entire Reaction.

(3) In the process of disaster relief, the government should automatically analyse the disaster situation, control the overall situation of the disaster macroscopically, increase decision-making information, and make more accurate strategies.

(4) Appropriate relief supplies amount should be applied for a single resident when they are rescued. It is necessary to mobilize the initiative of residents and reduce the pressure of the government on disaster relief.

\section{Data Availability}

The data used to support the findings of this study are available from the corresponding author upon request.

\section{Conflicts of Interest}

The authors declare that they have no known competing financial interests or personal relationships that could have appeared to influence the work reported in this paper.

\section{Acknowledgments}

The authors would like to thank Wei Zhou, Tianyu Wan, and $\mathrm{Xu}$ Sun for their helpful suggestions and technology support. This research was supported in part by National Natural Science Foundation of China (Grant no. 71603197).

\section{References}

[1] T. Wang, J. B. Liu, and G. Li, “A real options-based decisionmaking model for infrastructure investment to prevent rainstorm disasters," Production and Operations Management, vol. 28, no. 11, pp. 2699-2715, 2019.

[2] N. Altay and W. G. Green, "OR/MS research in disaster operations management," European Journal of Operational Research, vol. 175, no. 1, pp. 475-493, 2006.

[3] M. Janssen, N. Lee, and A. Cresswell, "Advances in multiagency disaster management: key elements in disaster research," Information Systems Frontiers, vol. 12, no. 1, pp. 1-7, 2010.

[4] J. Buckland and M. Rahman, "Community-based disaster management during the 1997 red river flood in Canada," Disasters, vol. 23, no. 2, pp. 174-191, 2010.

[5] Y. Shi, "Risk analysis of rainstorm waterlogging on residences in Shanghai based on scenario simulation," Natural Hazards, vol. 62, no. 2, pp. 677-689, 2012.

[6] X. Zhang, G. M. Hu, and Y. Xu, "Urban rainwater utilization and its role in mitigating urban waterlogging problems-A case study in nanjing, China," Water Resources Management, vol. 26, no. 13, pp. 3757-3766, 2012.
[7] X. Wu, Z. D. Yu, and R. L. Wilby, "An evaluation of the impacts of land surface modification, storm sewer development, and rainfall variation on waterlogging risk in Shanghai," Natural Hazards, vol. 63, no. 2, pp. 305-323, 2012.

[8] R.-S. Quan, "Rainstorm waterlogging risk assessment in central urban area of Shanghai based on multiple scenario simulation," Natural Hazards, vol. 73, no. 3, pp. 1569-1585, 2014.

[9] Y. F. Ning, W. Y. Dong, L. S. Lin et al., "Analyzing the causes of urban waterlogging and sponge city technology in China," in Proceedings of the 2nd International Conference on Advances in Energy Resources and Environment Engineering (ICAESEE), vol. 59, 2017, Article ID 012047.

[10] Y. Zhang, P. Luo, S. Zhao et al., "Control and remediation methods for eutrophic lakes in recent 30 years," Water Science \& Technology, vol. 81, no. 6, pp. 1099-1113, 2020.

[11] T. Sewell, R. E. Stephens, D. Dominey-Howes et al., "Disaster declarations associated with bushfires, floods and storms in New South Wales, Australia between 2004 and 2014," Scientific Reports, vol. 6, Article ID 36369, 2016.

[12] D. Satoh, R. Y. Takano, and T. Mochida, "Reduction of communication demand under disaster congestion using control to change human communication behavior without direct restriction," Computer Networks, vol. 134, pp. 105-115, 2018.

[13] Ö. Ergun, L. Gui, J. L. Heier Stamm, P. Keskinocak, and J. Swann, "Improving humanitarian operations through technology-enabled collaboration," Production and Operations Management, vol. 23, no. 6, pp. 1002-1014, 2014.

[14] P. Luo, Y. Sun, S. Wang et al., "Historical assessment and future sustainability challenges of Egyptian water resources management," Journal of Cleaner Production, vol. 263, Article ID $121154,2020$.

[15] B. Su, H. Huang, and Y. Li, "Integrated simulation method for waterlogging and traffic congestion under urban rainstorms," Natural Hazards, vol. 81, no. 1, pp. 23-40, 2016.

[16] Z. Zheng, S. Qi, and Y. Xu, "Questionable frequent occurrence of urban flood hazards in modern cities of China," Natural Hazards, vol. 65, no. 1, pp. 1009-1010, 2013.

[17] Z. Xudong, Y. Kun, P. Shuangyun et al., "The study of urban rainstorm waterlogging scenario simulation based on GIS and SWMM model-take the example of Kunming Dongfeng East Road catchment area," in Proceedings of the 21st International Conference on Geoinformatics (Geoinformatics), International Conference on Geoinformatics, Kai Feng, China, June 2013.

[18] S. Chowdhury, A. Emelogu, M. Marufuzzaman, S. G. Nurre, and L. Bian, "Drones for disaster response and relief operations: a continuous approximation model," International Journal of Production Economics, vol. 188, pp. 167-184, 2017.

[19] C. Lai, X. Chen, X. Chen, Z. Wang, X. Wu, and S. Zhao, “A fuzzy comprehensive evaluation model for flood risk based on the combination weight of game theory," Natural Hazards, vol. 77, no. 2, pp. 1243-1259, 2015.

[20] M. P. Scaparra and R. Church, "Protecting supply systems to mitigate potential disaster," International Regional Science Review, vol. 35, no. 2, pp. 188-210, 2012.

[21] A. M. Caunhye, X. Nie, and S. Pokharel, "Optimization models in emergency logistics: a literature review," SocioEconomic Planning Sciences, vol. 46, no. 1, pp. 4-13, 2012.

[22] C. Wang, J. Wu, X. Wang et al., "Application of the hidden Markov model in a dynamic risk assessment of rainstorms in Dalian, China," Stochastic Environmental Research and Risk Assessment, vol. 32, no. 10, pp. 2045-2056, 2018. 
[23] J. Salmerón and A. Apte, "Stochastic optimization for natural disaster asset prepositioning," Production and Operations Management, vol. 19, no. 5, pp. 561-574, 2010.

[24] M. Mahootchi and S. Golmohammadi, "Developing a new stochastic model considering bi-directional relations in a natural disaster: a possible earthquake in Tehran (the Capital of Islamic Republic of Iran)," Annals of Operations Research, vol. 269, no. 1-2, pp. 439-473, 2017.

[25] Y. Sawada and Y. Takasaki, "Natural disaster, poverty, and development: an introduction," World Development, vol. 94, pp. 2-15, 2017.

[26] J. W. Delleur and Y. Gyasi-Agyei, "Prediction of suspended solids in urban Sewers by transfer function model," Water Science \& Technology, vol. 29, no. 1-2, pp. 171-179, 1994.

[27] H. Yu, C. G. Huang, and C. Wu, "Application of the stormwater management model to a piedmont city: a case study of Jinan City, China," Water Science and Technology, vol. 70, no. 5, pp. 858-864, 2014.

[28] D. S. Bisht, C. Chatterjee, S. Kalakoti, P. Upadhyay, M. Sahoo, and A. Panda, "Modeling urban floods and drainage using SWMM and MIKE urban: a case study," Natural Hazards, vol. 84, no. 2, pp. 749-776, 2016.

[29] X. Pan, K. Han, and K. H. Law, "A multi-agent based framework for the simulation of human and social behaviors during emergency evacuations," Ai \& Society, vol. 22, no. 2, pp. 113-132, 2007.

[30] C. Fikar, P. C. P. Hirsch, and P. C. Nolz, "Agent-based simulation optimization for dynamic disaster relief distribution," Central European Journal of Operations Research, vol. 26, no. 2, pp. 423-442, 2017.

[31] S. Iwanaga and A. Namatame, "Contagion of evacuation decision making on real map," Mobile Networks and Applications, vol. 21, no. 1, pp. 206-214, 2016.

[32] K. Zhu, H. J. Tang, and J. C. LiGong, "Using a combinatorial auction-based approach for simulation of cooperative rescue operations in disaster relief," International Journal of Modeling, Simulation, and Scientific Computing, vol. 09, no. 4, Article ID 1850035, 2018.

[33] M. Hashemipour, J. S. Stuban, and J. Dever, "A disaster multiagent coordination simulation system to evaluate the design of a first-response team," Systems Engineering, vol. 21, no. 4, pp. 322-344, 2018.

[34] J. Tang, H. K. Zhu, and C. C. S. LiaoGong, "Using auctionbased task allocation scheme for simulation optimization of search and rescue in disaster relief," Simulation Modelling Practice and Theory, vol. 82, pp. 132-146, 2018.

[35] M. Zhang, S. R. Starbuck, S. S. LeeHwang, M. Choi, and H.-S. Lee, "Distributed and interoperable simulation for comprehensive disaster response management in facilities," Automation in Construction, vol. 93, pp. 12-21, 2018.

[36] A. Park, A. Pietro, P. Kini et al., "A platform for disaster response planning with interdependency simulation functionality,"vol. 417, pp. 183-197, in Proceedings of the 7th Annual IFIP Working Group 11.10 International Conference on Critical Infrastructure Protection (ICCIP), Advances in Information and Communication Technology, vol. 417, pp. 183-197, George Washington University, Washington, DC, USA, March 2013.

[37] R. J. Dawson, R. Peppe, and M. Wang, "An agent-based model for risk-based flood incident management," Natural Hazards, vol. 59, no. 1, pp. 167-189, 2011.

[38] Q. Yang, Y. Sun, X. Liu et al., "MAS-based evacuation simulation of an urban community during an urban rainstorm disaster in China," Sustainability, vol. 12, no. 2, pp. 1-19, 2020.
[39] Q. Yang, X. Sun, X. Liu et al., "Multi-agent simulation of individuals' escape in the urban rainstorm context based on dynamic recognition-primed decision model," Water, vol. 12, no. 4, Article ID 1190, 2020.

[40] Q. Hu and N. Kapucu, "Information communication technology utilization for effective emergency management networks," Public Management Review, vol. 18, no. 3, pp. 323-348, 2016.

[41] D. Cohen and S. Aner, "Common-value group contests with asymmetric information," Economics Letters, vol. 192, Article ID 109164, 2020.

[42] J. Ni, J. Zhao, and L. K. Chu, "Supply contracting and process innovation in a dynamic supply chain with information asymmetry," European Journal of Operational Research, vol. 288, no. 2, pp. 552-562, 2020.

[43] G. F. Nel, E. Smit, M. Leon, and Brummer, "The link between Internet investor relations and information asymmetry," South African Journal of Economic and Management Sciences, vol. 21, no. 1, pp. 1-10, 2018.

[44] V. Grimm, E. Revilla, U. Berger et al., "Pattern-oriented modeling of agent-based complex systems: lessons from ecology," Science, vol. 310, no. 5750, pp. 987-991, 2005.

[45] R. M. Axelrod, "The complexity of cooperation: agent-based models of competition and cooperation," Complexity, vol. 3, no. 3, pp. 46-48, 1998.

[46] C. M. Macal and M. J. North, "Tutorial on agent-based modelling and simulation," Journal of Simulation, vol. 4, no. 3 , pp. 151-162, 2010.

[47] E. Bonabeau, "Agent-based modeling: methods and techniques for simulating human systems. Proceedings of the sackler colloquium on adaptive agents, intelligence, and emergent human organization-capturing complexity through agent-based modeling," in Proceedings of the National Academy of Sciences of the Unite States of America, vol. 99, no. 3, pp. 7280-7287, Irvine, CA, USA, October 2001.

[48] V. Grimm, U. Berger, F. Bastiansen et al., "A standard protocol for describing individual-based and agent-based models," Ecological Modelling, vol. 198, no. 1-2, pp. 115-126, 2006.

[49] G. Belyavsky, N. Danilova, and G. Ougolnitsky, “A markovian mechanism of proportional resource allocation in the incentive model as a dynamic stochastic inverse stackelberg game," Mathematics, vol. 6, no. 8, Article ID 131, 2018.

[50] S. Sharma, D. K. Ogunlana, and J. Grynovicki, "Modeling human behavior during emergency evacuation using intelligent agents: a multi-agent simulation approach," Information Systems Frontiers, vol. 20, no. 4, pp. 741-757, 2018.

[51] S. Taga, T. Matsuzawa, M. Takimoto et al., "Multi-agent base evacuation support system using MANET," in Proceedings of the 10th International Conference on Computational Collective Intelligence (ICCCI), Lecture Notes in Artificial Intelligence, vol. 11055, pp. 445-454, Bristol, UK, September 2018.

[52] J. Z. Leibo, V. Zambaldi, M. Lanctot et al., "Multi-agent reinforcement learning in sequential social dilemmas," in Proceedings of the 16th International Conference on Autonomous Agents and Multiagent Systems (AAMAS), pp. 464473, Sao Paulo, Brazil, May, 2017.

[53] N. Hooshangi and A. Asghar Alesheikh, "Agent-based task allocation under uncertainties in disaster environments: an approach to interval uncertainty," International Journal of Disaster Risk Reduction, vol. 24, pp. 160-171, 2017.

[54] N. Collier, "Repast: an extensible framework for agent simulation," University Of Chicago Social Science Research Building, vol. 36, pp. 371-375, 2003. 
[55] M. J. North, N. T. Collier, and J. R. Vos, "Experiences creating three implementations of the Repast agent modeling Toolkit," ACM Transactions on Modeling and Computer Simulation, vol. 16, no. 1, pp. 1-25, 2006.

[56] M. J. North, T. R. Howe, N. T. Collier et al., "The Repast simphony runtime system," in Proceeding of the Agent 2005 Conference on Generative Social Processes, Models, and Mechanisms, pp. 151-158, Chicago, IL, USA, October 2005.

[57] N. Malleson, L. A. Heppenstall, and L. See, "Crime reduction through simulation: an agent-based model of burglary," Computers, Environment and Urban Systems, vol. 34, no. 3, pp. 236-250, 2010.

[58] F.-Y. Wang, K. M. Carley, D. Zeng, and W. Mao, "Social computing: from social informatics to social intelligence," IEEE Intelligent Systems, vol. 22, no. 2, pp. 79-83, 2007.

[59] F. Y. Mao, X. Wang, L. Li et al., "Steps toward parallel intelligence," IEEE/CAA Journal of Automatica Sinica, vol. 3, pp. 345-348, 2016.

[60] B. Linghu, F. Chen, X. Guo et al., "A conceptual model for flood disaster risk assessment based on agent-based modeling," in Proceedings of the International Conference on Computer Sciences and Applications (CSA), pp. 369-373, International Conference on CSA, Wuhan, China, December 2013.

[61] C. F. Camerer, "When does "economic man" dominate social behavior?” Science, vol. 311, no. 5757, pp. 47-52, 2006.

[62] C. E. Fritz and E. S. Marks, "The NORC studies of human behavior in disaster," Journal of Social Issues, vol. 10, no. 3, pp. 26-41, 1954.

[63] J. Ghurye, G. Krings, and V. Frias-Martinez, "A framework to model human behavior at large scale during natural disasters," in Proceedings of the 2016 17th IEEE International Conference on Mobile Data Management (MDM), pp. 18-27, Porto, Portugal, June 2016.

[64] N. Parikh, R. J. Hayatnagarkar, M. V. Marathe, and S. Swarup, "A comparison of multiple behavior models in a simulation of the aftermath of an improvised nuclear detonation," $A u$ tonomous Agents and Multi-Agent Systems, vol. 30, no. 6, pp. 1148-1174, 2016.

[65] A. Dan, E. Owens, and O. Rozenbaum, "Do information releases increase or decrease information asymmetry? New evidence from analyst forecast announcements," Journal of Accounting \& Economics, vol. 62, no. 1, pp. 121-138, 2016.

[66] J. Martínez-Ferrero, D. Ruiz-Cano, and I.-M. García-Sánchez, "The causal link between sustainable disclosure and information asymmetry: the moderating role of the stakeholder protection context," Corporate Social Responsibility and Environmental Management, vol. 23, no. 5, pp. 319-332, 2016.

[67] L. Pearce, "Disaster management and community planning, and public participation: how to achieve sustainable hazard mitigation," Natural Hazards, vol. 28, no. 2-3, pp. 211-228, 2003.

[68] F. Thomalla, E. T. Spanger-Siegfried, and J. G. Rockström, "Reducing hazard vulnerability: towards a common approach between disaster risk reduction and climate adaptation," Disasters, vol. 30, no. 1, pp. 39-48, 2006.

[69] V. Strandh and N. Eklund, "Emergent groups in disaster research: varieties of scientific observation over time and across studies of nine natural disasters," Journal of Contingencies and Crisis Management, vol. 26, no. 3, pp. 329-337, 2018.

[70] I. Noy, "The macroeconomic consequences of disasters," Journal of Development Economics, vol. 88, no. 2, pp. 221-231, 2009.
[71] R. J. Burby, "Hurricane katrina and the paradoxes of government disaster policy: bringing about wise governmental decisions for hazardous areas," The Annals of the American Academy of Political and Social Science, vol. 604, no. 1, pp. 171-191, 2006.

[72] B. Raphael, "Crowds and other collectives: complexities of human behaviors in mass emergencies," Psychiatry: Interpersonal and Biological Processes, vol. 68, no. 2, pp. 115-120, 2005.

[73] A. K. Chakravarty, "A contingent plan for disaster response," International Journal of Production Economics, vol. 134, no. 1, pp. 3-15, 2011.

[74] S. H. Kang and M. Skidmore, "The effects of natural disasters on social trust: evidence from South Korea," Sustainability, vol. 10, no. 9, pp. 1-16, 2018.

[75] Y. Liu, J. Tian, F. Gengzhong et al., "A relief supplies purchasing model via option contracts," Computers \& Industrial Engineering, vol. 137, Article ID 106009, 2019. 